\title{
High Resolution Implantable Microsystem and Probe Design for Retinal Prosthesis
}

\author{
Mohammad Ismail Talukder ${ }^{*}$, Pepe Siy and Gregory W. Auner
}

Department of Electrical and Computer Engineering, Wayne State University, Detroit, Michigan, USA

\begin{abstract}
By a retinal prosthesis, the researchers have been able to stimulate a limited number of neurons (around 100) by biphasic current stimulus to reproduce an image spatially by multiplexing technique. For functional restoration of sight (visual acuity 20/80), we are to stimulate at least 2500 neurons $/ \mathrm{mm}^{2}$. We are far behind that target. The time required by biphasic current stimulus, the sequential stimulation by multiplexing technique, and the conventional probes used for stimulation limits our ability to stimulate large number of neurons and maintains the persistence of vision. To address this problem, we have designed high resolution donut probes and used them in designing neural implant chip (NIC) applying parallel multiplexing technique, which helped us stimulate large number of neurons. This paper presents the design of a donut probe and an implantable CMOS-based 5x5 array NIC to demonstrate that idea. This 5x5 array NIC is scalable to any larger array. It uses external clock, which makes it suitable for any data rate. The programmable biphasic width controller (BWC) used in this design is capable of generating various kinds of stimulus for stimulation. NIC doesn't need address to route the pixels, which reduces the data transmission overhead. $0.5 \mu \mathrm{m}$ CMOS technology is used to fabricate NIC with donut probes. Test results verify our technique of increasing the resolution.
\end{abstract}

Keywords: Parallel multiplexing, stimulator, retinal prosthesis, implantable, donut probes.

\section{INTRODUCTION}

We know that photoreceptors of retina help us see. Due to age-related macular degeneration (AMD) or retinitis pigmentosa (RP), photoreceptors degenerate or cease to exist [1]. The goal of most of the researches is to develop a retinal prosthesis that will replace photoreceptors and pass visual signal to the next level. Epiretinal prosthesis pass signal to the ganglion cells, while subretinal prosthesis relay signals to the bipolar cells. Research is in progress on both kinds of prosthesis [2-16].

Biphasic current waveform (shown in Fig. (1)) is used to stimulate the neurons for its charge balancing capabilities. There are four parameters associated with this waveform. They are amplitude, width, interphase delay, and frequency. The typical values of all these parameters for retinal prosthesis as reported in various papers $[1,7,17,18]$ are: $10 \mu \mathrm{A}$ $600 \mu \mathrm{A}$ for amplitude, $100 \mu \mathrm{s}-2 \mathrm{~ms}$ for width, $0-1 \mathrm{~ms}$ for delay, and $10-125 \mathrm{~Hz}$ for frequency. Medical experiments have estimated that the equivalent impedance for the retinal tissue of RP and AMD patient is about 10Kohm [7]. The prosthesis, whether it is intended for epiretinal or subretinal implant, should be able to generate a biphasic current waveform of the above-mentioned parameters.

We see some successes of retinal stimulation by only limited number of electrodes $[7,19,20]$. So far the vision is limited to creation of stars like phosphene by an array of $5 \times 5$ [7] or 10x10 [19]. In terms of density, it is only 20 electrodes $/ \mathrm{mm}^{2}$ [19]. For functional restoration of sight, the required visual acuity is $20 / 80$, which is equivalent to 2500

*Address correspondence to this author at the Department of Electrical and Computer Engineering, Wayne State University, Detroit, Michigan, USA; E-mail: mitalukder@gmail.com $\mathrm{pixel} / \mathrm{mm}^{2}$ [21]. That means we are to excite as many as 2500 electrodes $/ \mathrm{mm}^{2}$. We are far behind that target. Two main factors that are limiting our ability to achieve high resolution are the conventional electrodes that we are using for stimulation and sequential stimulation by biphasic stimulus.

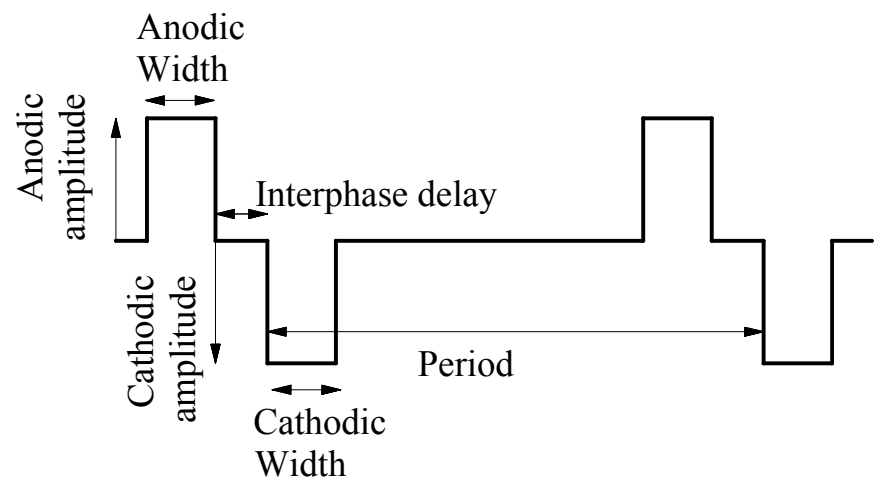

Fig. (1). Biphasic current waveform.

Electrodes are the interface between microsystems and bio-cells. The ideal interface is one-to-one interface. Though we have been able to establish some sort of interface after so many years of research, it is very crude. Neurons are millions in numbers, whereas our successfully built prostheses have only a few hundred electrodes at best. Though we have micro- and nano-technologies, we couldn't build prosthesis with effective resolution. Effort is being made to increase the resolution. The resolution depends on a number of factorslike the geometry of the probes, the type of prosthesis, extends of damage of the patient, the distance of the probes from the target cells, the amplitude/duration/frequency of stimulus, etc. All these play a role in controlling the resolution. But what we have found is that the geometry of the 
probe plays a major role [22]. Conventional probes [7, 17, $20,23]$ mostly used to stimulate neurons are pointing, monopolar, bipolar, etc. We have found that the resolutions of these probes are not good. The electric field generated by these probes spread wider reducing the resolution. We have designed a donut probe, which is far better than the conventional probes $[22,24]$. In our study, we have found that donut probe has $33 \%$ better resolution and $44 \%$ lesser potential drop (lesser resistance) than the conventional probes [22, 24]. In section 7, the design of such a probe is given. Another thing that we want in our probe is the lowest possible stimulation current to generate action potential. The thresholds found by various research groups to generate action potential vary widely. It varies from $0.15 \mu \mathrm{A}$ to $1121 \mu \mathrm{A}$, and the related pulse duration varies from $75 \mu$ s to $2 \mathrm{~ms}[8,17]$. The reasons of these wide variations most probably are the condition of the individual subjects, the type of prosthesis (epi-retinal or sub-retinal) they used, the type of probes (pointing, monopolar, bipolar, etc.), the geometry of the probe, and the location of the probe with respect to the target cells. If the geometry of the probe is bigger than what is required then the threshold current would increase or if the probe is smaller, then the threshold current could decrease, but may create unsafe current density in the electrode and tissue interface. The spacing between stimulating and return electrodes also affects the threshold. In designing probe, all these must be taken into consideration. In [22], a methodology of designing a donut probe and an array of probes is developed, which has been utilized to optimize all the parameters.

The time required by biphasic stimulus, and sequential stimulation by multiplexing technique also limits our ability to stimulate a large number of neurons, and maintain the persistence of vision. Typical values of biphasic stimulus suggest that the duration of biphasic pulse could be as long as $5 \mathrm{~ms}$. The persistence of vision $\left(1 / 30^{\text {th }}\right.$ of a second) gives us $33.33 \mathrm{~ms}$ to complete one frame. If we apply multiplexing technique, and stimulate each neuron for $5 \mathrm{~ms}$, then only 6 electrodes could be stimulated within this time frame. So large scale stimulation required by a retinal prosthesis is a big challenge. Simple multiplexing technique won't work for large scale stimulation. To address this problem, parallel multiplexing technique is applied [1] is also trying the similar approach. By this technique it is possible to excite a large number of neurons within the persistence of vision. Though 6 electrodes could be excited through sequential multiplexing technique, in this design only 5 electrodes are considered to allow extra time for synchronization, which will be explained later. So the total number of electrodes is divided into 5 groups, and parallel stimulation is applied to all the electrodes of a group, and multiplexing among the groups. In this way, it is possible to excite as many neurons as we want by biphasic current stimulus, and still maintain the persistence of vision. To demonstrate this idea, a $5 \times 5$ array NIC is designed, fabricated, and tested. It needs only 4 wires to interface with the wireless receiver, a huge reduction of number of wires compare to flexible retinal implant [25]. It is scalable to a larger array. It uses external clock for its timing making it suitable for any data rate. It has a programmable biphasic width controller (BWC), which can generate monophasic or biphasic current stimulus with or without interphase delay.

\section{SYSTEM OVERVIEW}

The overall system of a retinal prosthesis and its block diagram are shown in Fig. (2). It is basically a two units systems - one is extraocular and another intraocular unitmagnetically coupled together. The intraocular unit is implanted inside the eye, while the extraocular unit is mounted on the eyeglasses. Extraocular unit has a CCD camera, an image processor, an encoder, and a transmitter built on the eyeglass. High-resolution image from a CCD camera is reduced to lower resolution matching the array of electrodes by image processor, which is then encoded and transmitted wirelessly after time multiplexing. The intraocular unit is implemented in two chips - one is wireless receiver and another NIC as shown in Fig. (2a). Wireless receiver recovers each pixel and clock, and generates necessary power for the chip from its $13.56 \mathrm{MHz}$ carrier frequency. NIC is implanted in the retina to stimulate the healthy cells. It converts each pixel into biphasic current stimulus, and applies it to a $5 \times 5$ array arranged in $2 \mathrm{D}$ to reproduce a form vision.

\section{DESIGN OF PROSTHESIS}

The block diagram of the NIC is shown in Fig. (3). Four main functional blocks of the chip are data receiving register (DRR), biphasic width controller (BWC), current stimulator (CS), and neural stimulator (NS). These blocks are controlled by the neural implant chip controller (NICC). In the following sections, the detailed design and function of each block are presented.

\subsection{Data Receiving Register (DRR)}

DRR is designed (Fig. 4) to handle 40 bits of data. $5 \times 5$ array NS has 5 rows and 5 columns. If each pixel is 8 bits deep, then the required total length of a row of DRR is 40 bits. DRR is a double buffering first-in first-out (FIFO) serial to parallel converter. The 40-bit data is serially inputted to the 40-bit shift register (DFF), then latch to the 40-bit latch register $(\mathrm{LCH})$.

\subsection{Biphasic Width Controller (BWC)}

The design of BWC is shown in Fig. (5). It is designed with three similar units for controlling anodic width (P), interface delay, and cathodic width $(\mathrm{N})$. Each unit has a memory register (LCH0-LCH5) and a synchronous binary counter composed of 6 toggle flip-flops (TFF0-TFF5) as shown in Fig. (5b). When input L of TFF is low, bit $\mathrm{P}$ is loaded in DFF, else it toggles with CLK when T is high. EN is the count enable, and $\mathrm{RC}$ is the ripple carry of the counter. The input CFG is used to latch the configuration bits ( $\mathrm{P} 0$ $\mathrm{P} 17)$ in the memory register, while input $\overline{\mathrm{LD}}$ to load the configuration bits in the counter. 
(a)

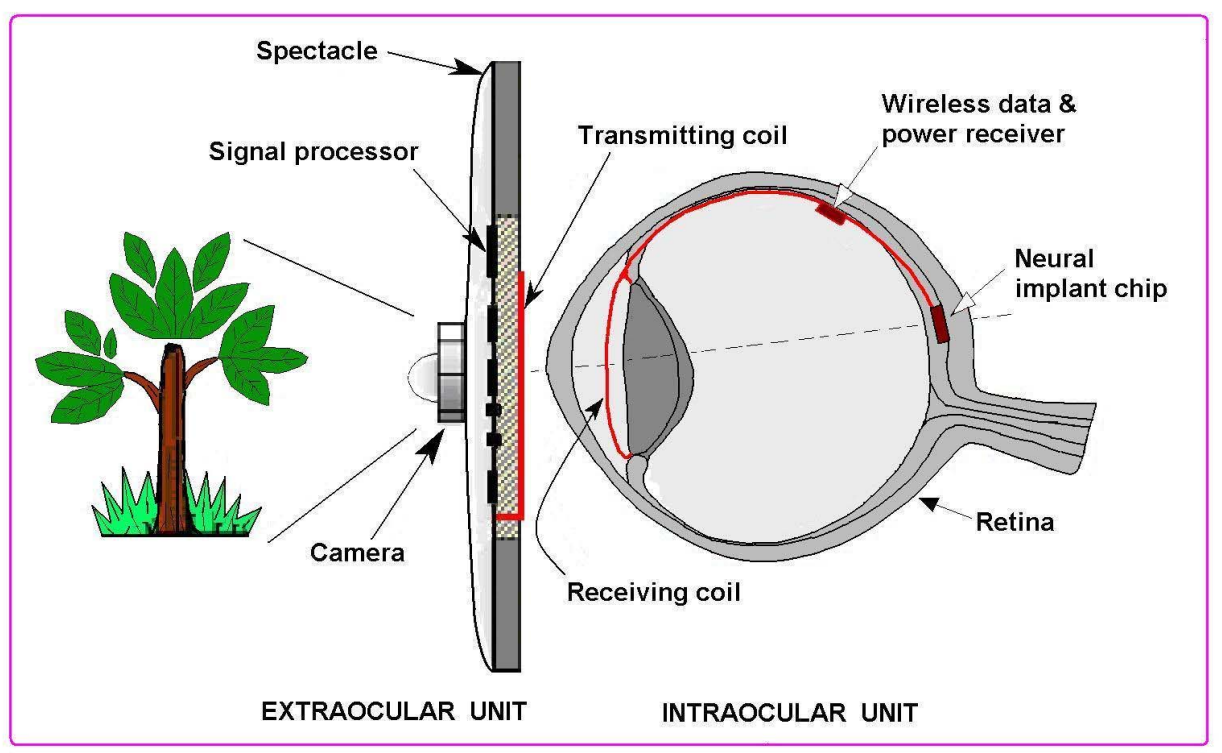

(b)

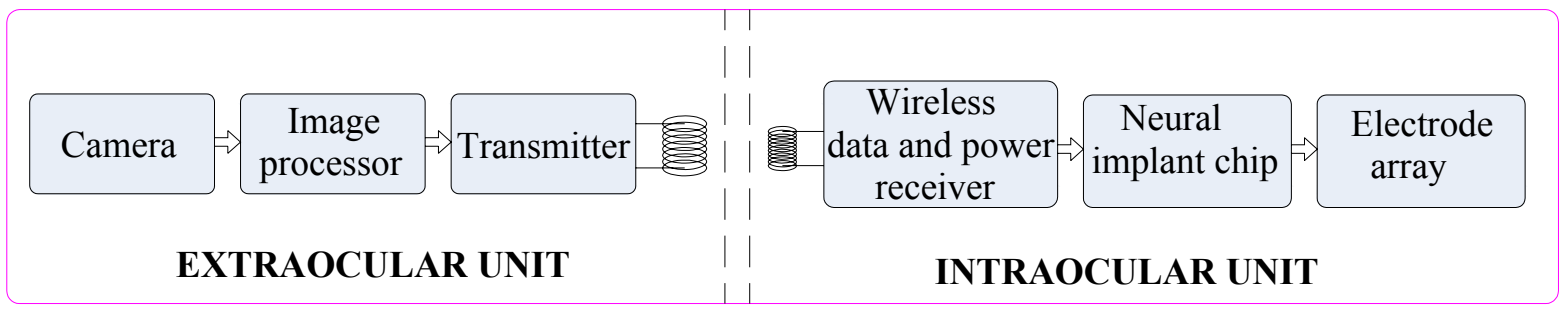

Fig. (2). (a) Complete artificial vision restoration system (b) Block diagram of the retinal prosthesis

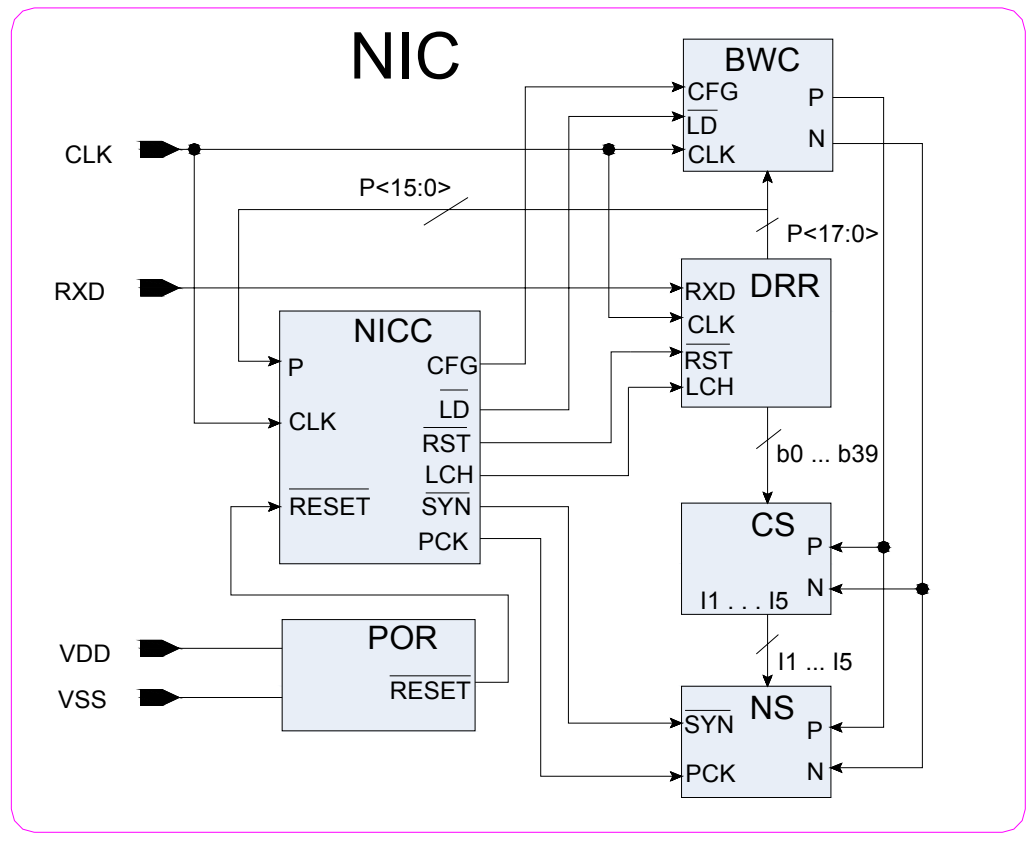

Fig. (3). Block diagram of neural implant chip (NIC) 


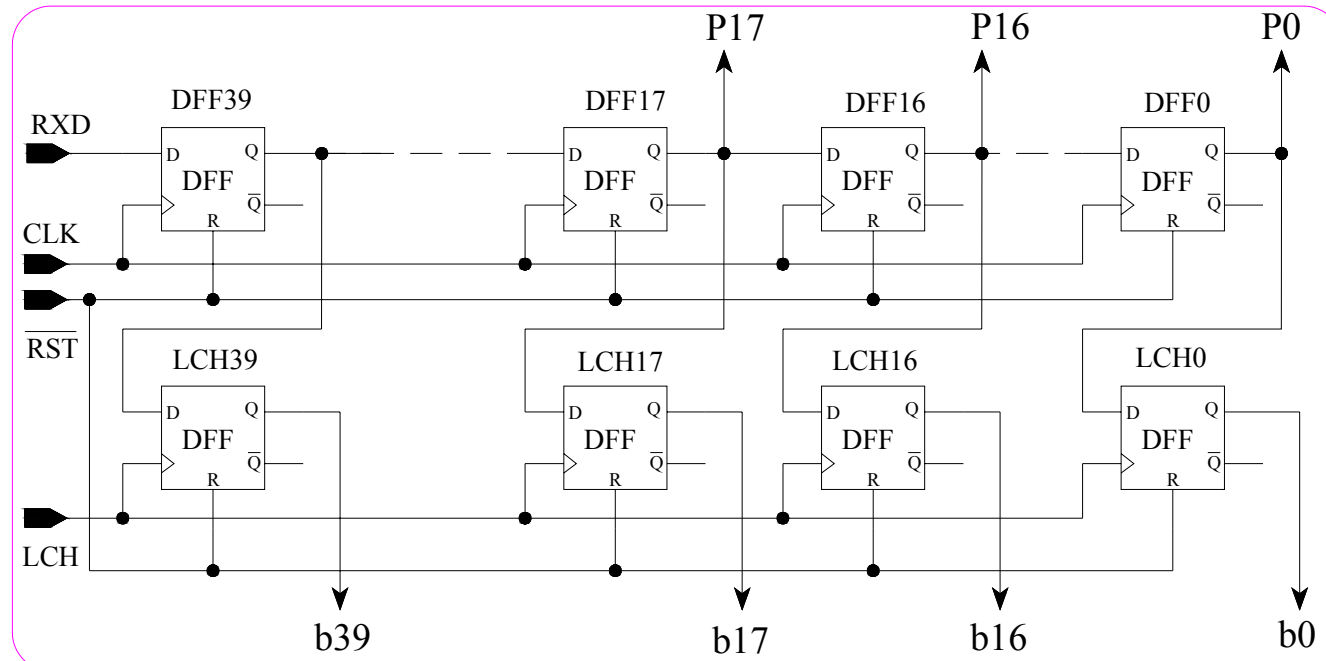

Fig. (4). Schematic diagram of DRR

When $\overline{\mathrm{LD}}$ is pulled low briefly, the counters are loaded with configuration bits from memory registers, and anodic width counter starts counting from its loaded number with the rising edge of CLK. On reaching count 63, the output RC goes high enabling interface delay counter, setting $\mathrm{P}$ low, and locking anodic width counter by i0. Similarly, interphase delay counter enables cathodic width counter when it counts 63 , and sets $\mathrm{N}$ high allowing generation of cathodic width, as $\mathrm{RC}$ of interphase delay counter is high at this time. Cathodic width counter starts counting from its loaded number with the rising edge of CLK and on count 63, it sets N low locking itself by feed back inverter. At the end, all the three counters get locked and remain so till they receive another reset by $\overline{\mathrm{LD}}$, which is initiated at the beginning of next row. As counters stop at 63 from the programmed bits, the unit should be programmed with lower number for longer width or delay, as the width or delay is the difference between the set number and 63 . With this design, we can generate only anodic or cathodic pulse by setting the other to zero or biphasic pulse without delay by setting interphase delay to zero. The width can be given by:

Anodic/cathodic/interphase delay in time $=\frac{63-\text { setting of } 6 \text { bit width in decimal }}{f}$

where, $f$ is the clock frequency.

\subsection{Current Stimulator (CS)}

The design of CS is shown in Fig. (6). It is an 8-bit current converter and converts binary-weighted data (b0...b7) into equivalent analog current (I). It is designed using regulated cascode current sink (RCCS) as shown in Fig. (6b), which uses negative feedback to stabilize the output current, and to increase the output impedance. Control of $\mathrm{V}_{\text {bias1 }}$ by input could be enough, but the additional control by the OR gate helped us reduce the current surge during switching. CS is design for a resolution of $2.5 \mu \mathrm{A}$; for $10 \mathrm{~K} \Omega$ load, it can deliver $640 \mu \mathrm{A}$ at $7 \mathrm{~V}$, or $484 \mu \mathrm{A}$ at $5 \mathrm{~V}$ for full 8 -bit data.

The simulation and test of CS is plotted in Fig. (7). The test result is very close to the simulation result. CS is tested with $5 \mathrm{~V}$ and $10 \mathrm{~K} \Omega$ load for the whole range of 8-bit data. The test results reveal that the CS has $2.5 \mu \mathrm{A}$ resolution, and is linear up to $463 \mu \mathrm{A}$ corresponding to decimal input of 190 . Maximum current is $489 \mu \mathrm{A}$ at decimal input value of 255 .

\subsection{Neural Stimulator (NS)}

Probe Design: The structure of donut probe is shown in Fig. (8). It has two flat electrodes - one is central and another donut electrode. Both these electrodes are embedded in the silicon substrate with the top surface exposed to the tissue. So these electrodes conduct current through the top surface only. The surface areas of both the electrodes are made equal to let them have equal current carrying capacity.

The specifications of the donut probe design are given in Table 1. Details are given in [22].

It has been shown in $[22,24]$ that donut probe has better electric field penetration, lesser spreading of electric field (means higher resolution), and posses least resistance to the current flow compare to the traditional electrodes. Donut probe has $33 \%$ better resolution, $44 \%$ lesser resistance than many of the conventional probes. In our neural stimulator circuit design, we have used this probe to improve the resolution.

Circuit Design: The design of $5 \times 5$ array NS is shown in Fig. (9). It has an array of probes (P11-P55), and a decoder (DFF1-DFF5). Each probe has four switches, which are controlled by two AND gates, which are controlled by the decoder and the BWC. Probe mentioned in Fig. (8) is grown based on CMOS technology. The central and donut electrodes are fabricated on top metal-3 layer. Beneath the electrodes, the switches and gates are grown. There are five current stimulating buses $\left(I_{1}\right.$ to $\left.I_{5}\right)$; each of them carries the 
(a)

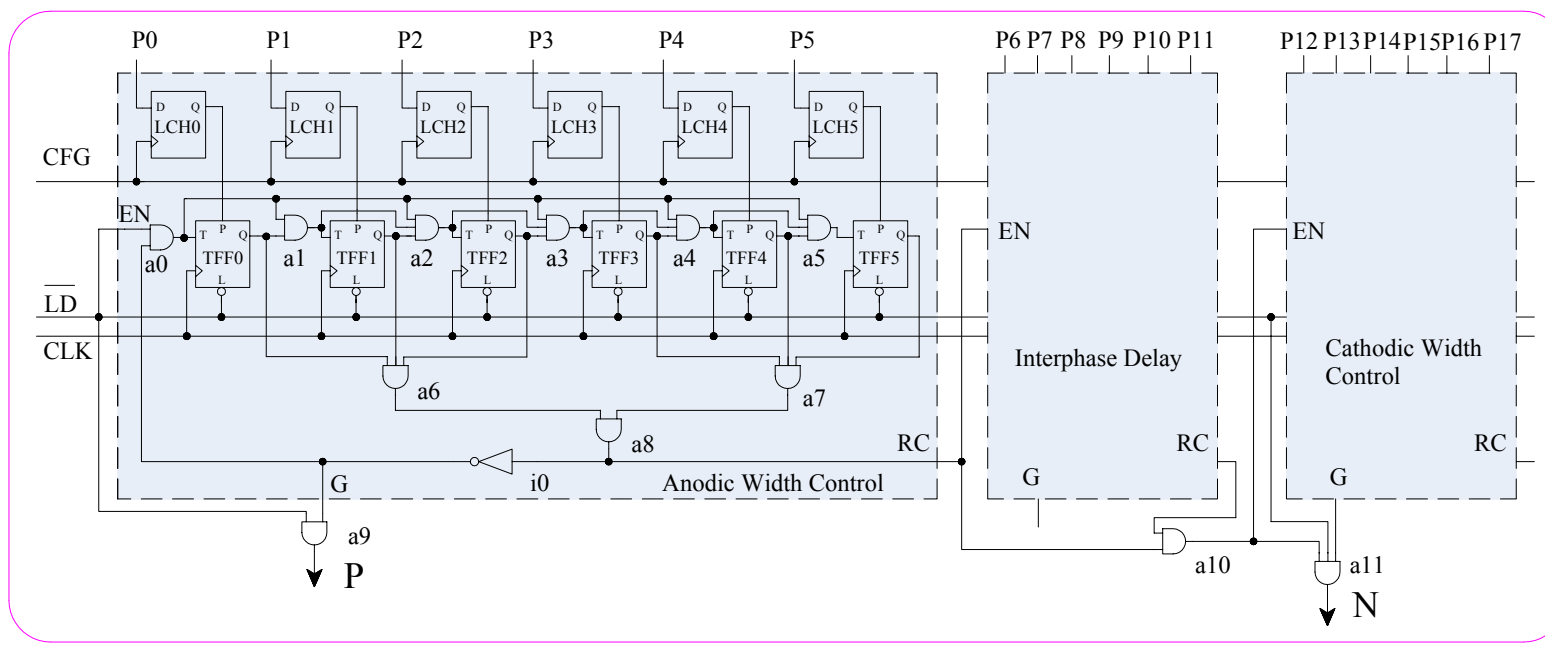

(b)

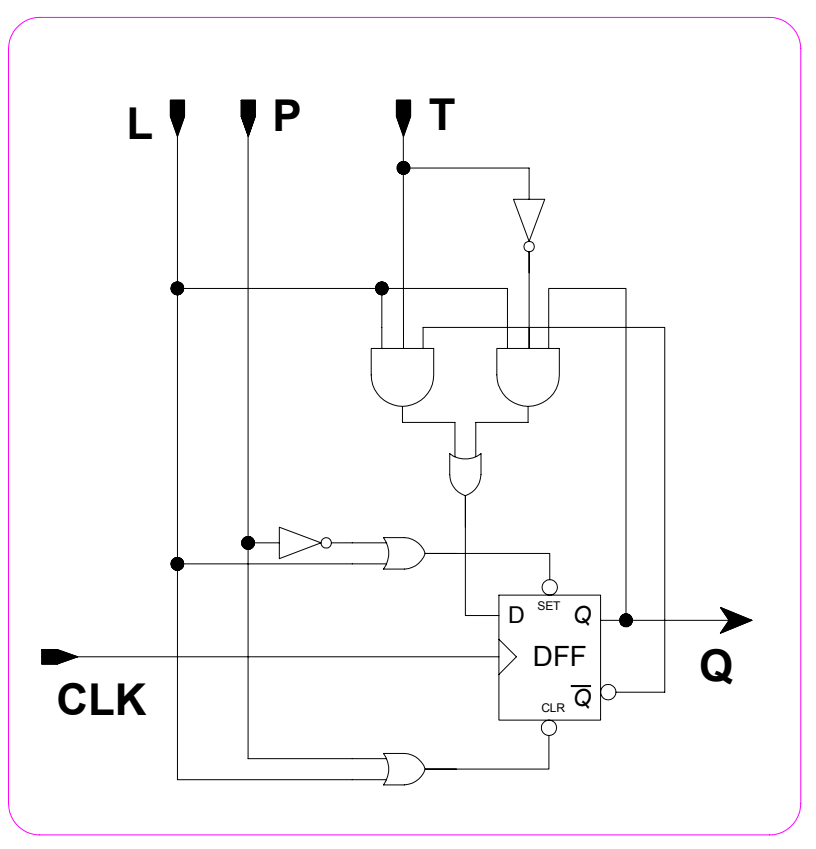

Fig. (5). (a) Biphasic width controller (BWC), (b) Toggle flip flop (TFF).

time-multiplexed stimulus for all the probes of a column. PCK is the clock for the decoder, which is 40 times slower than the data clock CLK. With start ( $\overline{\mathrm{SYN}}$ low), decoder points to DFF0 as it is a set DFF, while other are clear DFFs. In the next PCK cycle (which occurs after 40 CLK cycles, during which data of first row are loaded and latched in DRR, and converted into analog currents $\left(\mathrm{I}_{1}-\mathrm{I}_{5}\right)$ by CS), decoder points to the first row (output of DFF1 is high) and five different stimulus currents are applied to the five probes of the first row, the duration of which are controlled by $\mathrm{P}$ and N. Before the rising edge of next PCK cycle, DRR is again loaded with new data for the next row selected by the decoder (DFF2), which are then converted into analog currents $\left(\mathrm{I}_{1}-\mathrm{I}_{5}\right)$ by $\mathrm{CS}$, and are applied to the probes of new row. This pattern goes on till the end of $5^{\text {th }}$ row, and then it starts all over again. So this way, parallel stimulation is being applied to all the probes of a row, and multiplexing among the rows.

\subsection{Neural Implant Chip Controller (NICC)}

NICC is the main controller of the NIC. It controls BWC, DRR, CS, and NS through outputs $\overline{\mathrm{RST}}, \mathrm{CFG}, \overline{\mathrm{LD}}, \mathrm{LCH}$, $\overline{\mathrm{SYN}}$, and PCK. It has three inputs ( $\overline{\mathrm{RESET}}, \mathrm{CLK}$, and 
(a)

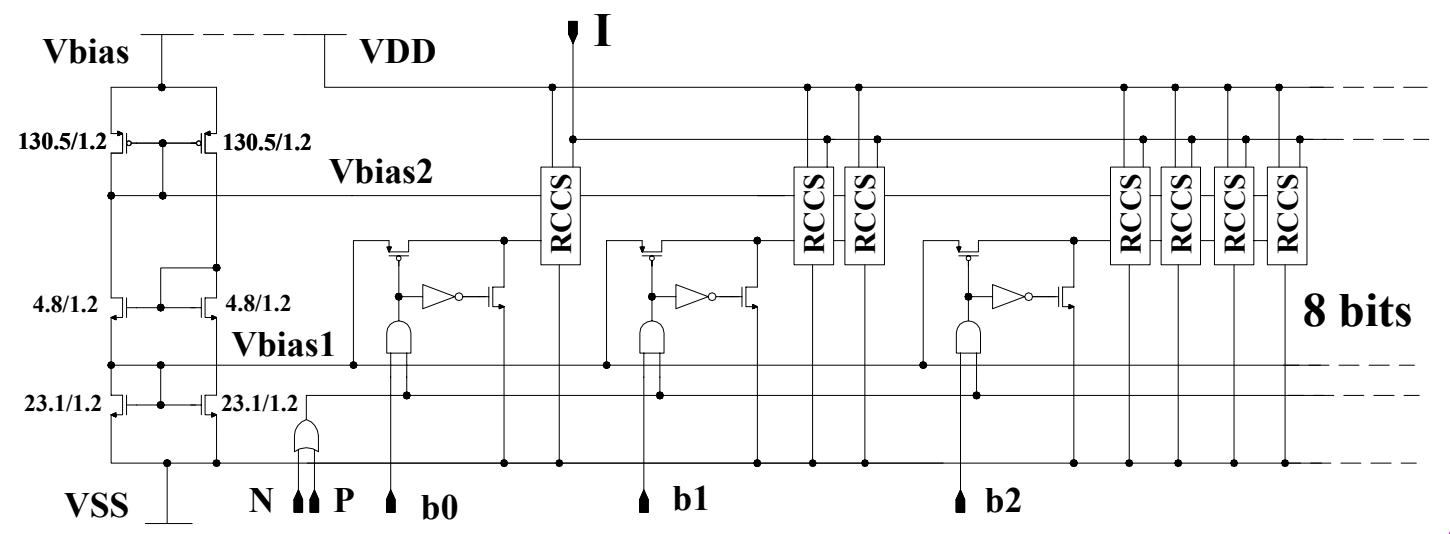

(b)

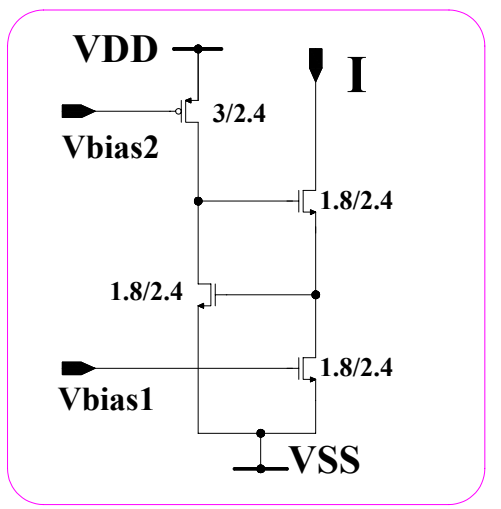

Fig. (6). (a) Current stimulator, (b) Regulated cascade current sink (RCCS).

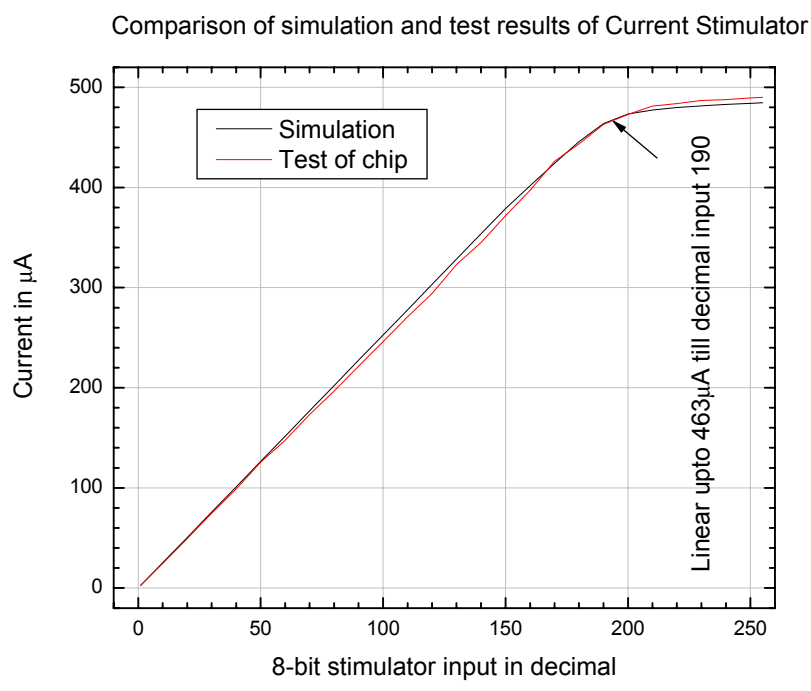

Fig. (7). Simulation and test of current stimulator.

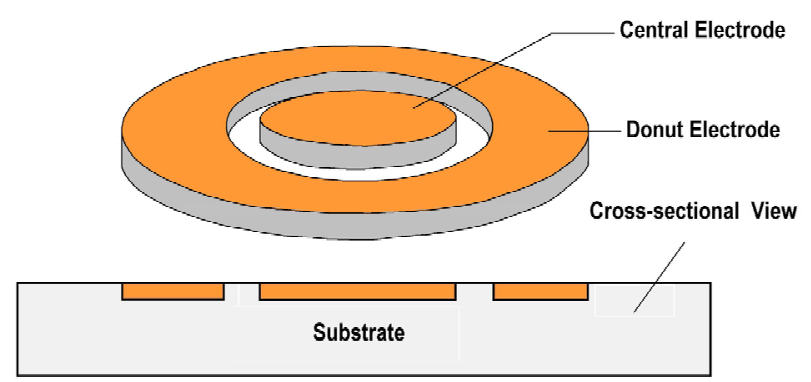

Fig. (8). Structure of a donut probe.

$\mathrm{P}<15$ : $0>$ ). It monitors part of the received data in the DRR through $\mathrm{P}<15$ : $0>$. The block diagram of NICC is shown in Fig. (10). It is composed of two counters (ctr40 and ctr6), and one state machine (sm). ctr40 keeps track of the 40 bits data of a row. When 40 bits are shifted in the DRR, it issues a pulse $(\mathrm{C} 40 \mathrm{~F})$ for half cycle. This pulse works as a clock for sm and ctr6. ctr6 keeps count of rows. When it counts 6 (5 
Table 1. Specifications of Donut Probe and Probe Array for $20 \mu m$ Penetration

\begin{tabular}{|l|c|}
\hline \multicolumn{1}{|c|}{ Parameters/Dimensions } & Value \\
\hline \hline Penetration & $20 \mu \mathrm{m}$ \\
\hline Stimulating current & $15.8 \mu \mathrm{A}$ \\
\hline Radius of central electrode $(\mathrm{r})$ & $15 \mu \mathrm{m}$ \\
\hline Spacing bet. central \& donut electrodes & $20 \mu \mathrm{m}$ \\
\hline Inner radius of donut electrode $\left(\mathrm{r}_{1}\right)$ & $35 \mu \mathrm{m}$ \\
\hline Outer radius of donut electrode $\left(\mathrm{r}_{2}\right)$ & $38 \mu \mathrm{m}$ \\
\hline Thickness of electrodes & $2 \mu \mathrm{m}$ \\
\hline Mini. spacing between two probes & $150 \mu \mathrm{m}$ \\
\hline Resolution & $150 \mu \mathrm{m} \times 150 \mu \mathrm{m}$ \\
\hline Material & $\mathrm{IrO} \mathrm{x}_{\mathrm{x}}$ \\
\hline
\end{tabular}

rows and 1 sync packets), it generates a pulse (C6F) for half a cycle, signaling sm of completing a frame. Output $\overline{\mathrm{RST}}$ clears the shift register and latch of DRR, CFG configures the BWC, $\overline{\mathrm{LD}}$ loads the synchronous counter of $\mathrm{BWC}$ at the beginning of stimulation of each row, LCH latches 40 bits of data of a row in DRR, and $\overline{\text { SYN }}$ synchronizes the scanning process of NS. PCK works as a clock for NS. Output SYNC is used to reset the ctr40 at the end of count; while output SYNCF reset ctr6 when synchronization word is received at the end of 5 th row.

The state machine sm can be explained with state diagram and status of control signals shown in Fig. (11). When $\overline{\text { RESET }}$ is pulled low briefly, sm is forced to state $\mathrm{S} 0$ or if it is in any other state it returns to S0. In this state, all the control outputs are zero. The sm monitors $\mathrm{P}<15$ : $0>$ and stays at $\mathrm{S} 0$ till it finds the start word 0xEEEE. As soon as it senses the start word, it moves to $\mathrm{S} 1$ enabling the counter ctr40 by pulling SYNC high. When ctr 40 counts 40 , the sm moves to S2, where $\overline{\mathrm{RST}}$ is released and least significant 18 bits are latched by $\mathrm{CFG}$ as configuration word in BWC. sm then moves to $\mathrm{S} 3$ at the rising edge of clock CLK. $\overline{\mathrm{LD}}$ and $\overline{\mathrm{SYN}}$ are pulled high in this state enabling the synchronous counter in BWC and releasing the scanning mechanism of NS respectively. Data of the first row starts shifting in DRR. When 40 bits are counted, sm moves to S4 and LCH latches these data in DRR, and PCK advances the NS decoder to point to the first row. $\mathrm{C} 40 \mathrm{~F}$ increases the count of ctr6 by one and check whether $\mathrm{C} 6 \mathrm{~F}$ flag is true. If the $\mathrm{C} 6 \mathrm{~F}$ flag is false, the sm slides back to $\mathrm{S} 3$ and starts counting the data of second row. Thus the sm moves back and forth till the data of all the 5 rows and the sync word are received; sm then moves to S5. Data which is in DRR at this stage is the synchronization word. This word is checked with the preset word 0xAAAA. When sm finds the matching word, it advances to $\mathrm{S} 6$ resetting ctr 40 and ctr6. sm then moves back to $\mathrm{S} 3$ in the rising edge of next clock (CLK), and starts a new frame.

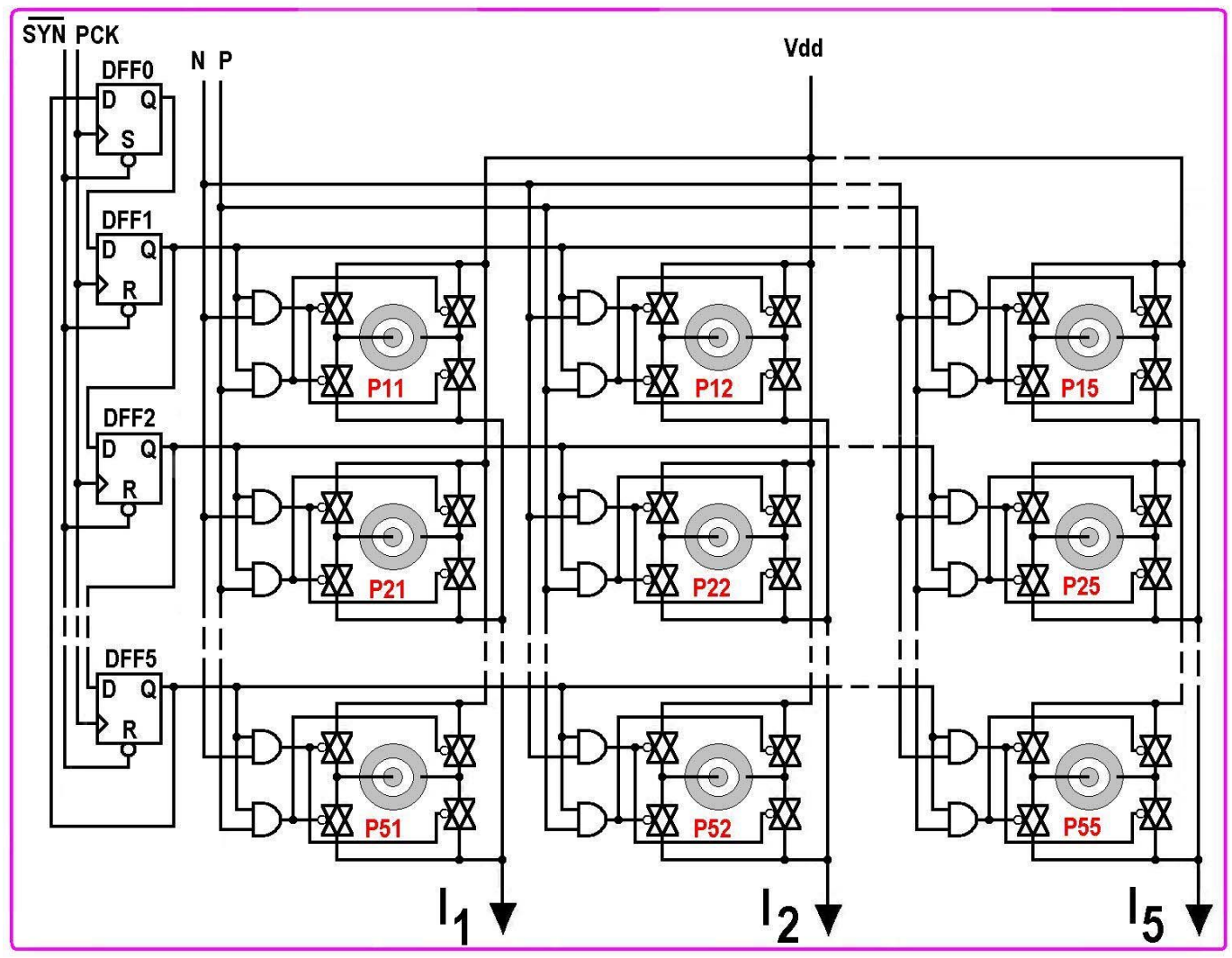

Fig. (9). $5 \times 5$ array neural stimulator (NS). 


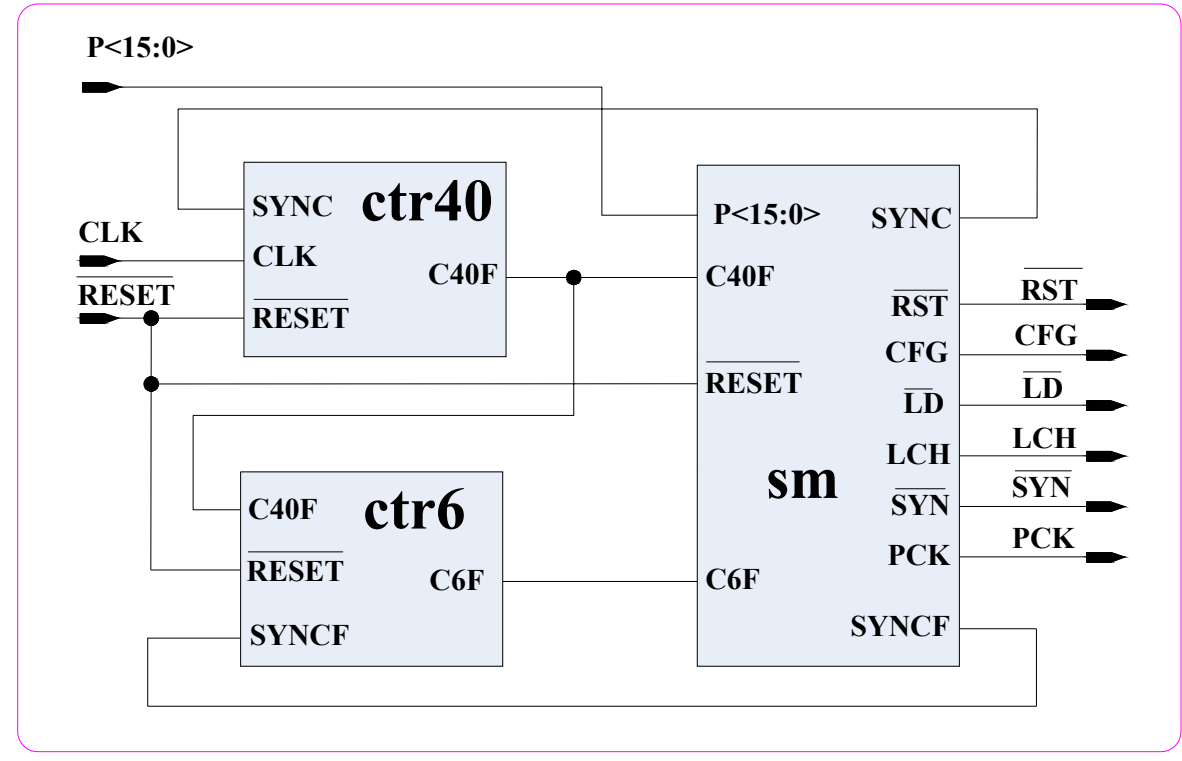

Fig. (10). Block diagram of the NICC.

The data transmission protocol of NIC is given in Table 2. ' $x$ ' stands for the padding bits, ' $d$ ' for the data of the rows, 'p', 'i', and ' $n$ ' stand for anodic, interphase delay and cathodic width bits respectively. The data transmission starts with start word, which is set here as '1110 $111011101110{ }_{2}$
(0xEEEE), followed by the configuration, data, and ends with the sync packet, which is "1010 $101010101010 "{ }_{2}$ (0xAAAA). Least significant 8 bits are the data of the $5^{\text {th }}$ probe, followed by the data of $4^{\text {th }}, 3^{\text {rd }}, 2^{\text {nd }}$, and $1^{\text {st }}$ probe. In the next frame, the start and configuration words are not

(a)

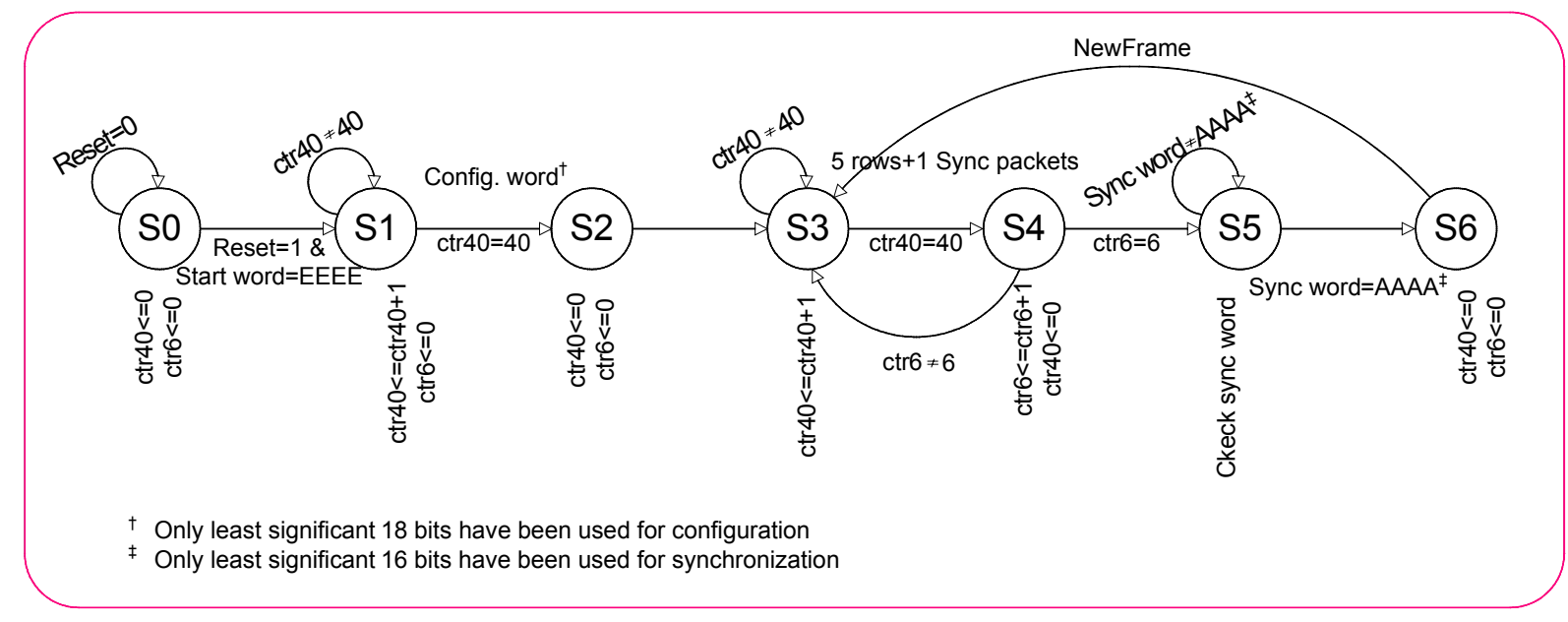

(b)

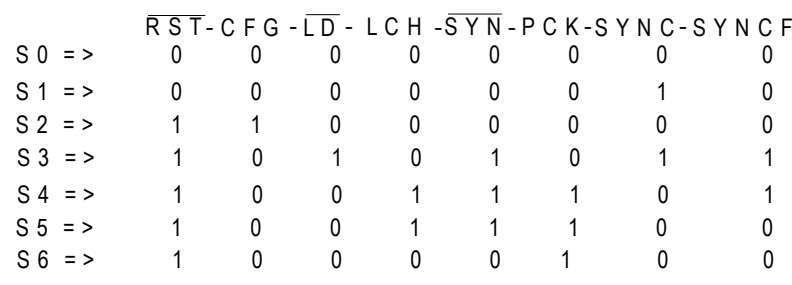

Fig. (11). (a) State diagram of the controller NICC (b) status of control signals at different states. 
Table 2. Protocol of Data Transmission

\begin{tabular}{|c|c|c|c|c|c|}
\hline Start word & $\mathrm{XxXX} \times \mathrm{xxx}$ & $\mathrm{xxxx} \times \mathrm{xxx}$ & Xxxx Xxxx & 11101110 & 11101110 \\
\hline Config & $\mathrm{XxXx}$ XXXX & $\operatorname{xxxx} \mathrm{xxxx}$ & xxxx xxpp & pppp i i i i & i i nn nnnn \\
\hline Row 1 data & dddd dddd & dddd dddd & dddd dddd & dddd dddd & dddd dddd \\
\hline : & & & & & \\
\hline Row 5 data & dddd dddd & dddd dddd & dddd dddd & dddd dddd & dddd dddd \\
\hline Sync word & $\operatorname{xxxx} \mathrm{xxxx}$ & $\operatorname{xxxx} \operatorname{xxxx}$ & XXXX XXXX & 10101010 & 10101010 \\
\hline
\end{tabular}

sent; transmission start directly with the data of row 1, row $2, \ldots$, and row 5 , and ends with sync word.

\subsection{Power on Reset (POR)}

To save silicon space, POR is designed with nine diodeconnected transistors instead of traditional resistors, a MOS capacitor instead of ceramic capacitor, and two Schmitt triggers as shown in Fig. (12). [26] has designed POR with diode string but used comparator. Instead of applying the total voltage, a part of it [input voltage $=(7 / 9) \times \mathrm{V}_{\mathrm{dd}}=(7 / 9) \times 5 \mathrm{~V}=$ $3.88 \mathrm{~V}]$ is applied to reduce the size of MOS capacitor added to the input of the Schmitt trigger to delay the rise of supply voltage. Usually $3-4 \mathrm{~ms}$ delay [26] is what we need to ensure the recovery of supply voltage and ensure a reset during this period.

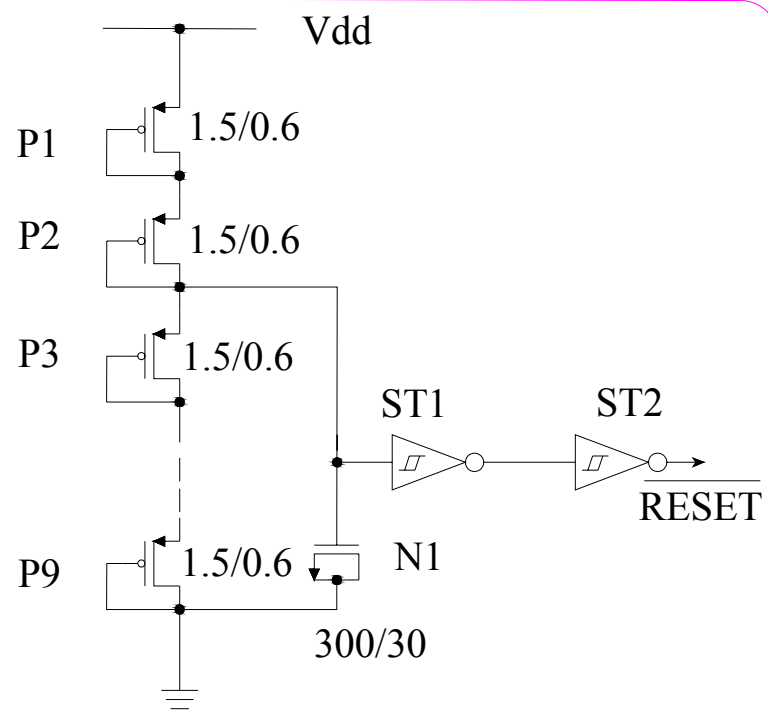

Fig. (12). Schematic diagram of power-on reset.

POR is tested by applying $5 \mathrm{~V}$ dc suddenly and monitoring the transient rise of the power and the reset. The result is presented in Fig. (13). From the plot, we see that the voltage rose to its applied value within $5.4 \mathrm{~ms}$ after switching, while reset stayed active for further $9.6 \mathrm{~ms}$ after reaching $5 \mathrm{~V}$. Though outside voltage rose to $5 \mathrm{~V}$ within $5.4 \mathrm{~ms}$, the MOS capacitor delayed reaching threshold for another $9.6 \mathrm{~ms}$. This longer delay will ensure better reset of the system under rated power supply.

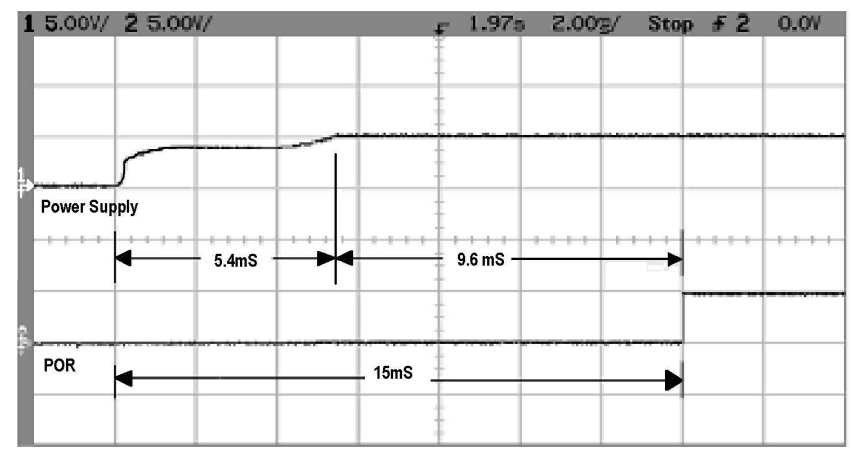

Fig. (13). Test of POR. 5V is applied all of a sudden and monitored the reset. Trace 1 is the transient voltage rise and Trace 2 is the reset.

\subsection{Neural Implant Chip (NIC)}

The microscopic view of NIC is shown in Fig. (14). It is designed according to the Fig. (3). To drive heavy loads, buffers are added. To test NIC, a test module is designed with many test points wired out of the chip. $0.5 \mu \mathrm{m}$ CMOS technology is used to design it in an area of $1.5 \mathrm{mmX} 3 \mathrm{~mm}$.

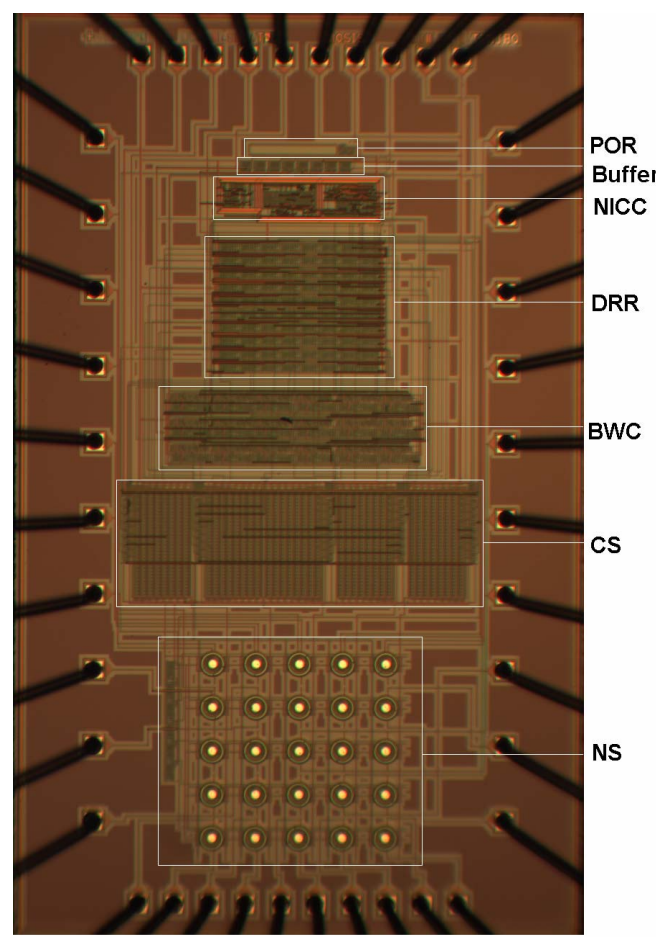

Fig. (14). Microscopic view of the test module of 5x5 array NIC. 


\section{TEST OF NEURAL IMPLANT CHIP (NIC)}

The test setup of NIC is shown in Fig. (15). The setup shows only the connections of a personal computer (PC operating on Windows XP), a microcontroller (PIC16F877 from Microchip Inc.), NIC (chip under test), and the oscilloscope (54622D from Agilent Technologies). To program the microcontroller, an evaluation board from Matrix Multimedia, UK, is used. Also to read the current flow through the loads (10Kohm resistors shown at the output of NIC), instrument amplifiers (not shown in the figure) are used. The PIC and NIC both are powered by $5 \mathrm{~V}$ dc i.e. $\mathrm{V}_{\mathrm{dd}}=5 \mathrm{~V}$ and $\mathrm{V}_{\mathrm{ss}}=0 \mathrm{~V}$. The instrument amplifier is powered by $\mathrm{V}_{\mathrm{dd}}=10 \mathrm{~V}$, $\mathrm{V}_{\mathrm{ss}}=0$, and $\mathrm{V}_{\text {ref }}=5 \mathrm{~V} .10 \mathrm{~V}$ is used in instrument amplifier to have a swing of $5 \mathrm{~V}$ in both the directions from mid-point, giving us the ability to read full drop of voltage across $10 \mathrm{Kohm}$ generated by anodic or cathodic waveform. Data table of Fig. (15) represent an image of letter ' $L$ '. To reproduce it, we are to transmit this table to the NIC. Instead of transmitting data from this table, a real time data can be read from a port of PIC (connected to a DSP) and send it directly. In this test, NIC is tuned to $2.5 \mu \mathrm{A}$ resolution corresponding to each binary digit. A clock of frequency $7.353 \mathrm{KHz}$ is used.

Basically 3 main tests are carried out in addition to checking the reset, start word, and synchronization word. They are:

Biphasic pulse width control test: This test is carried out by programming different configuration words. The widths set by configuration word 0x033DF3 are shown in Fig. (16a) and that set by 0x033DFB are shown in Fig. (16b). The configuration word 0x033DF3 will set anodic and cathodic widths each to 12 cycles, and interphase delay to 4 cycles. From Fig. (16a), we also see that they are 12 cycles long. Similarly configuration word 0x033DFB will set anodic width 12 , cathodic width 8 , and the interphase delay to 4 cycles and this is what we have in the Fig. (16b). In Fig. $(\mathbf{1 6 c}, \mathbf{d})$ monophasic waveforms are generated by the configuration words $0 x 03 \mathrm{BEFF}$ and $0 \mathrm{x} 03 \mathrm{FEFB}$ respectively. The configuration word $0 \mathrm{x} 03 \mathrm{BFFB}$ has created biphasic waveform without delay as shown in Fig. (16e), because it sets the interphase delay to zero.

Biphasic pulse amplitude control test: The data of each probe (P11, P12...P55) mentioned in Fig. (15) sets the amplitude of the biphasic waveform. By setting different values for these data, different amplitudes are tested. We have tested for data $0 \times 00,0 \times 01,0 \times 02,0 \times 04,0 \times 08,0 \times 10,0 \times 20$, $0 x 40,0 x 80$, and $0 x F F$ for each row. In Fig. (17), the outputs for data $0 \times 20$ and $0 \times 80$ in two different probes are presented. Measured output amplitudes are $0.8 \mathrm{~V}$ and $3.2 \mathrm{~V}$ respectively. This voltage across $10 \mathrm{Kohm}$ represents a current of $(0.4 \mathrm{~V} / 10 \mathrm{KOhm}) 40 \mu \mathrm{A}$ and $320 \mu \mathrm{A}$ which is 16 and 128 times stronger than the $2.5 \mu \mathrm{A}$ respectively. This result shows the linear dependence of the data with the amplitude. From other tests, it is found that the amplitude of the pulse is proportional to the data from $0 \mathrm{x} 01$ to $0 \mathrm{xB} 0$; the data above $0 \mathrm{xB} 0$ shows different degree of amplitude saturation of different channels as predicted from the test of CS mentioned in section 3.3. So for linear response, we are to avoid setting data above $0 x B 0$. For maximum value of data i.e. $0 x F F$, the maximum amplitude recorded is $4.3 \mathrm{~V}$. This is equal to $430 \mu \mathrm{A}$, which is close to the test result obtained in section

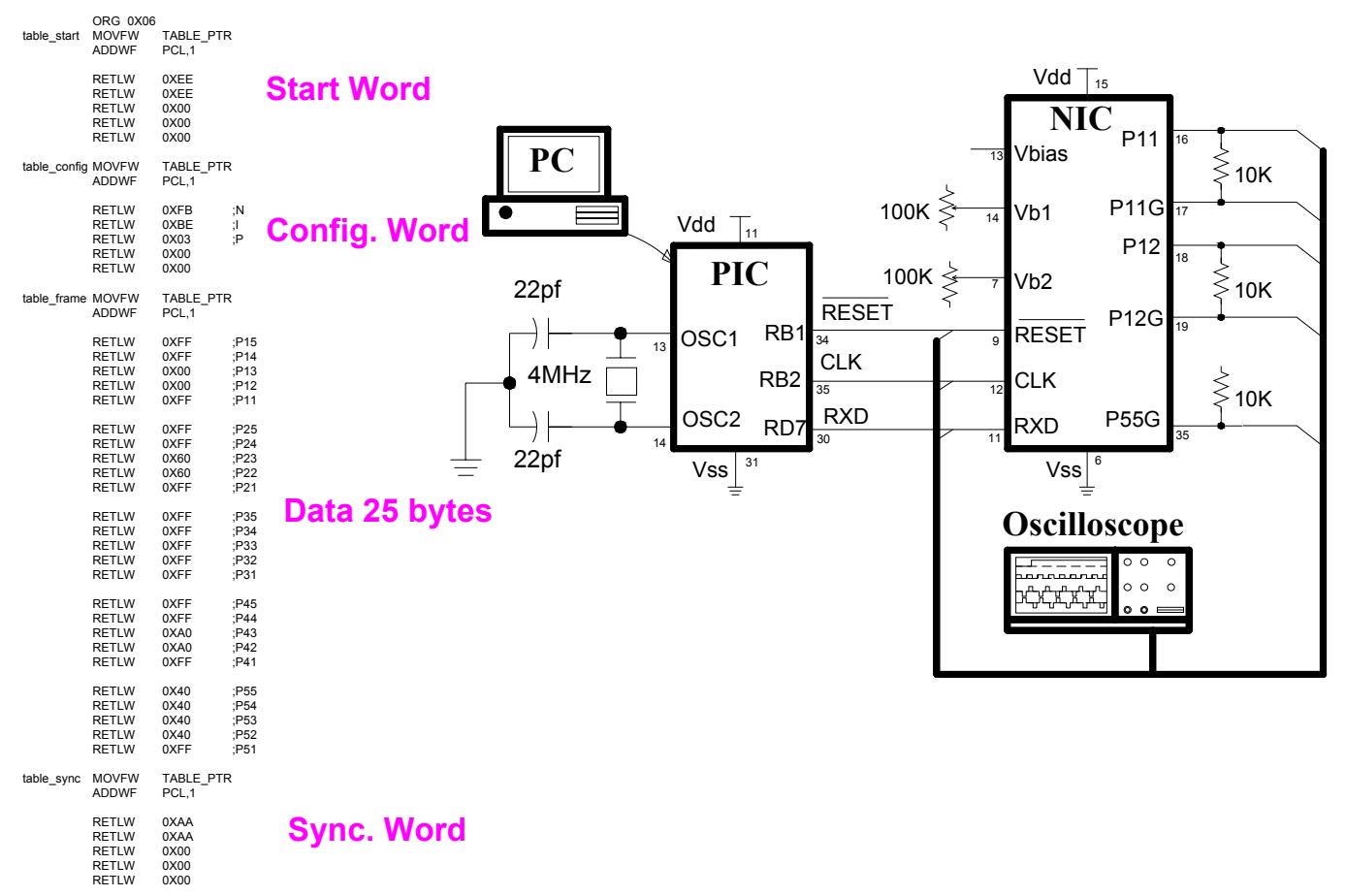

Fig. (15). Test setup of NIC. Microcontroller (PIC) is programmed with the data of letter "L" as shown in the table on left of the figure. PIC sends this data to the NIC continuously to stimulate the neurons. 
3.3 .

(a) Configuration word 0x033DF3

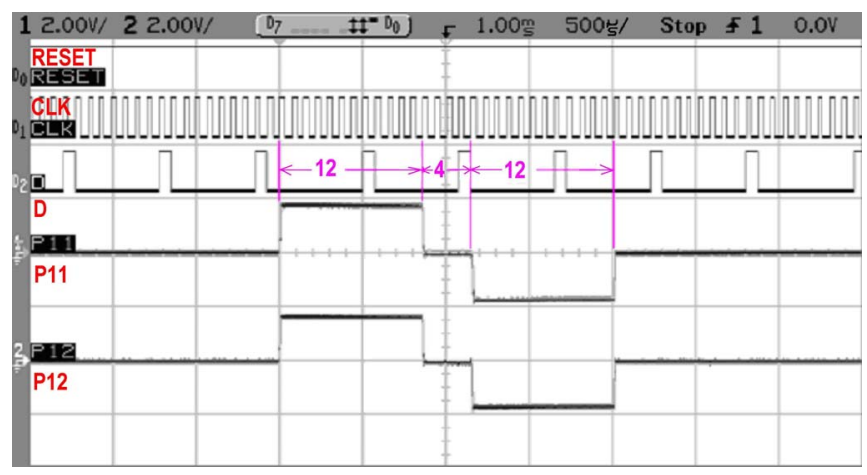

(b) Configuration word 0x033DFB

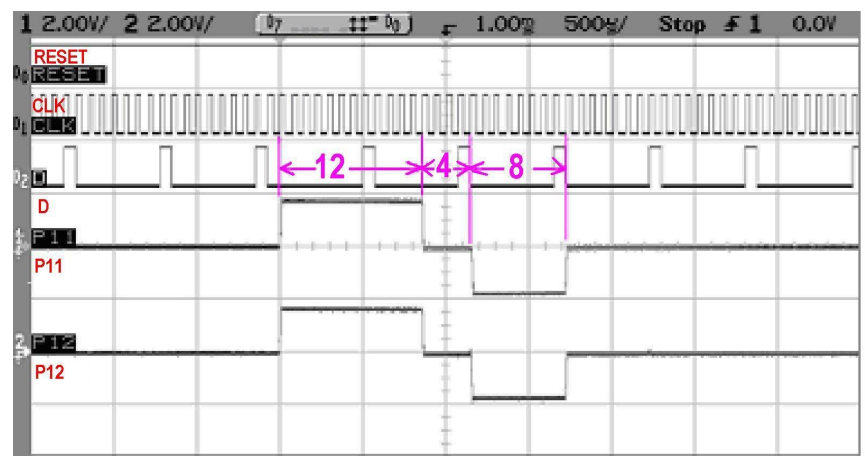

(c) Configuration word 0x03BEFF

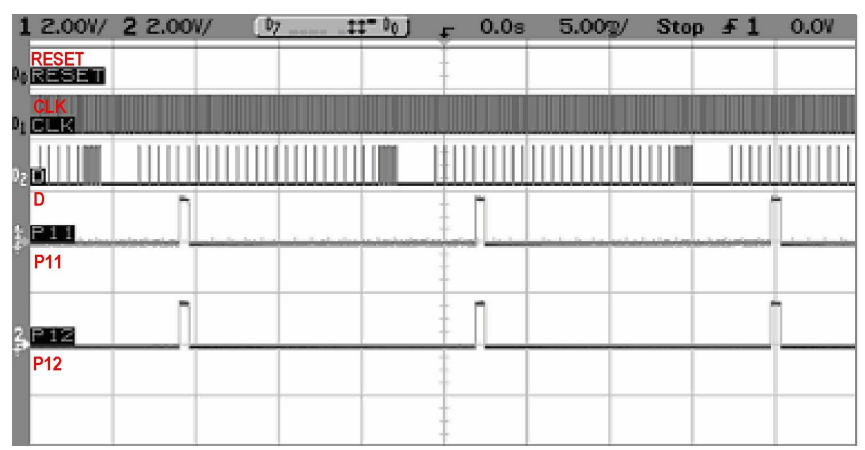

(d) Configuration word 0x03FEFB

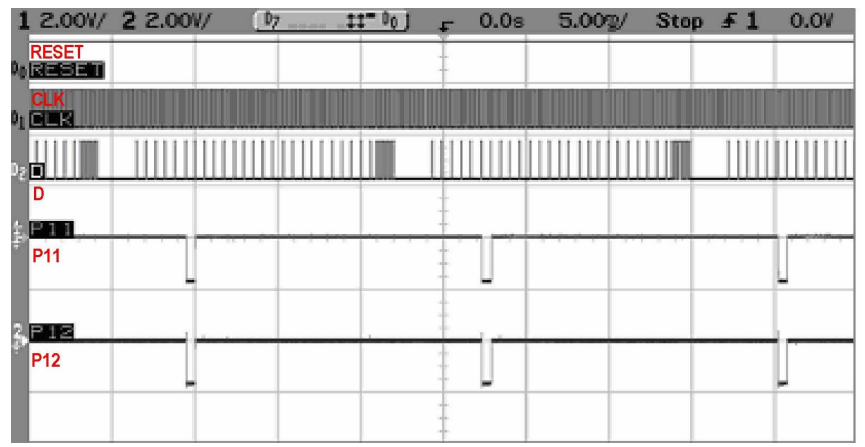

(Fig. 16) contd......

(e) Configuration word 0x03BFFB

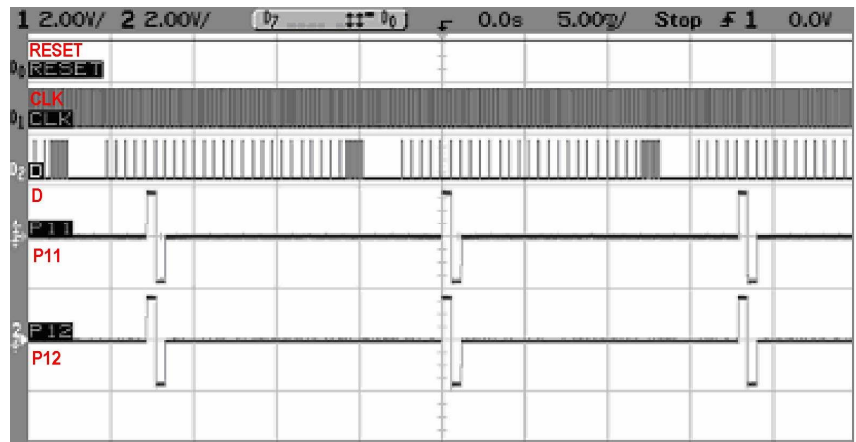

Fig. (16). Biphasic pulse width control test. Widths generated by configuration word (a) 0x033DF3 (b) 0x033DFB (c) 0x03BEFF (d) 0x03FEFB (e) 0x03BFFB.

(a) P21-P22

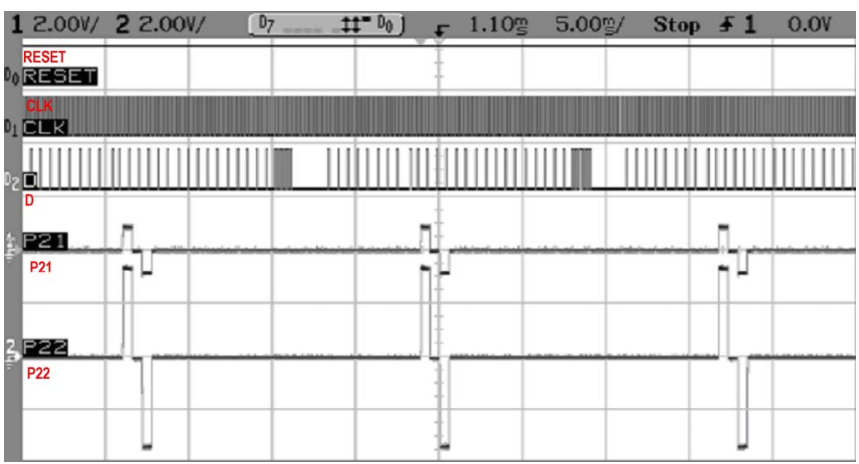

(b) P52 - P53

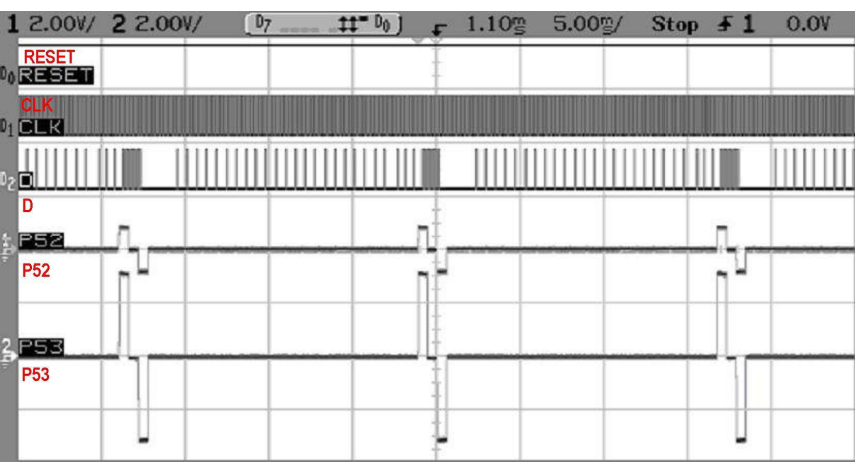

Fig. (17). Variable data loaded (a) $\mathrm{P} 21=0 \times 20, \mathrm{P} 22=0 \times 80$ (b) $\mathrm{P} 52$ $=0 \times 20, \mathrm{P} 53=0 \times 80$. Measured amplitudes are $0.8 \mathrm{~V}$ and $3.2 \mathrm{~V}$ respectively.

Parallel multiplexing stimulation test: Tests of parallel multiplexing stimulation are also presented in Fig. (18). In this test, it is found that all the probes of the same row (e.g. P11 and P12 of row1 or P51 and P55 of row 5 as shown in 18(a) and (g)) got activated simultaneously, while probes of different rows (e.g. P11 and P21, or P11 and P33, or others as shown in Fig. (18b-f)) took turn. It means the probes of a row are showing parallel stimulation while probes of different rows exhibiting multiplexed stimulation. The time difference between two consecutive rows (e.g. row 1 and row 2 as shown in Fig. (18b)) is 40 cycles, while time difference between row 1 and row 5 (e.g. P11 from row1 and P55 from 
row5 as shown in Fig. (18f)) is 5 times than the consecutive rows. This verifies that the parallel multiplexing stimulation is working.

(a) P11-P12

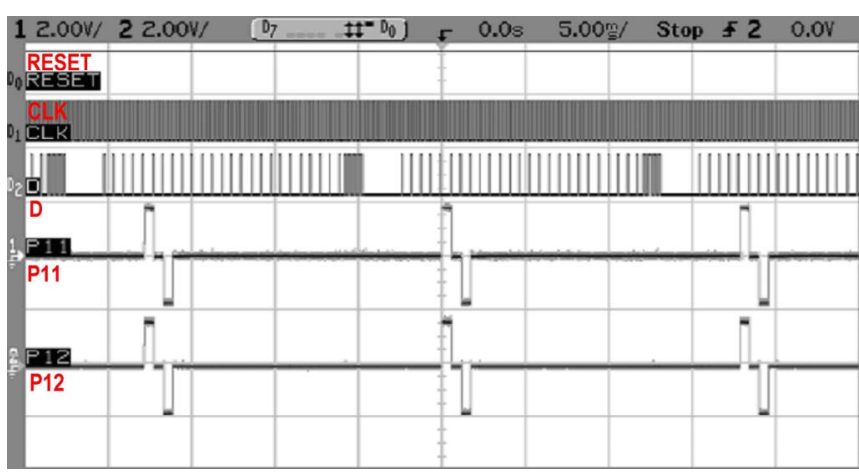

(b) P11 - P21

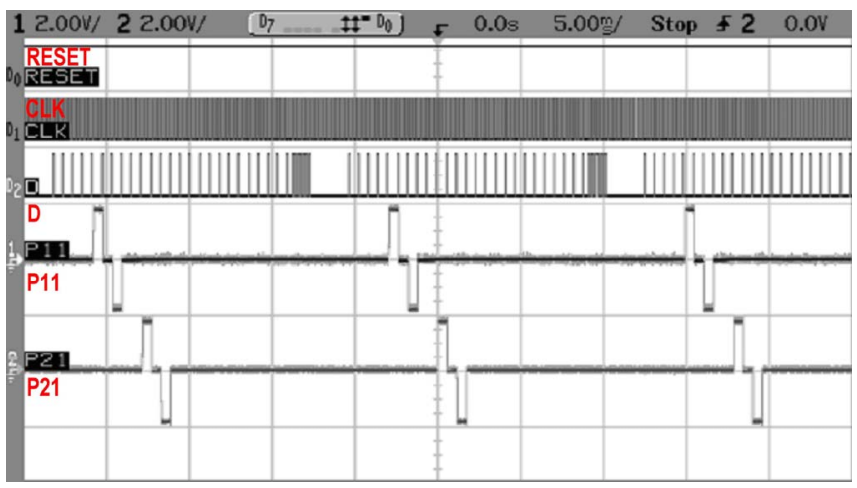

(c) P11 - P33

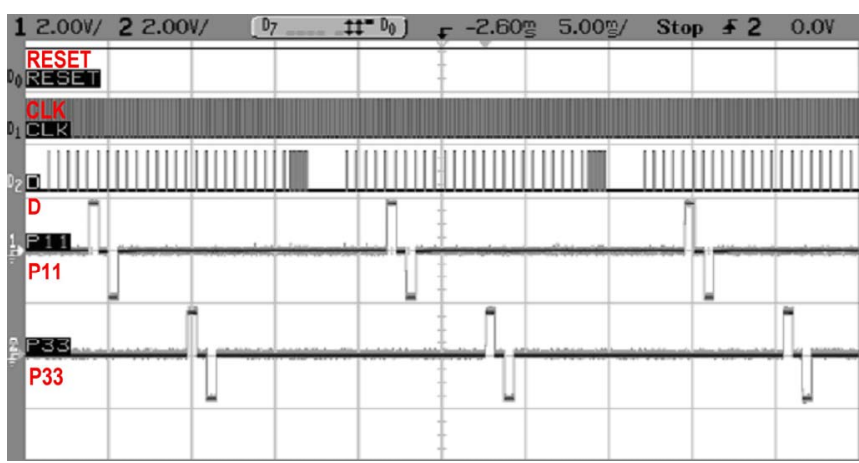

(d) P11 - P44

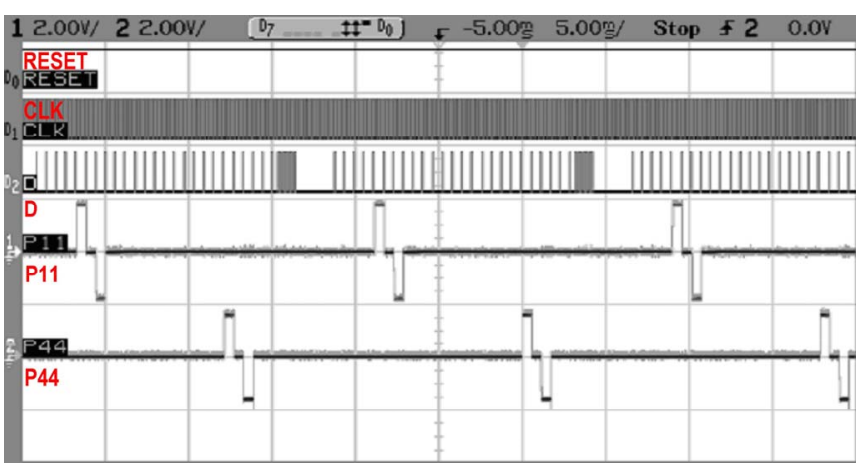

(Fig. 18) contd......

(e) P11 - P51

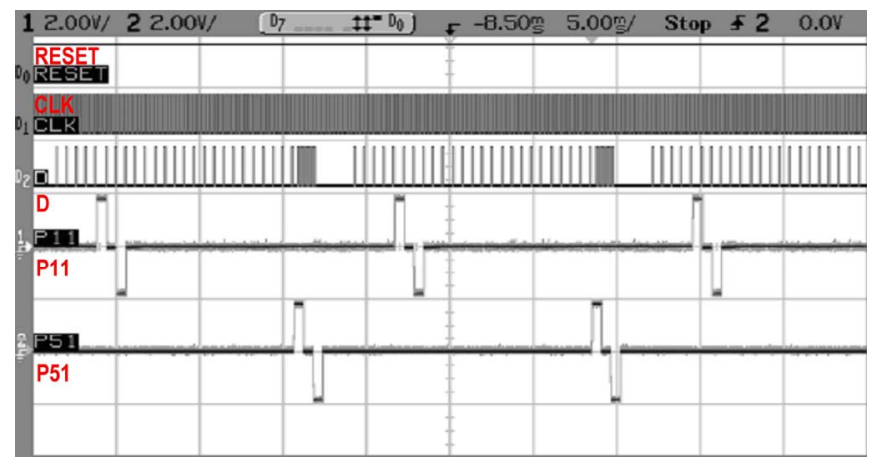

(f) P11 - P55

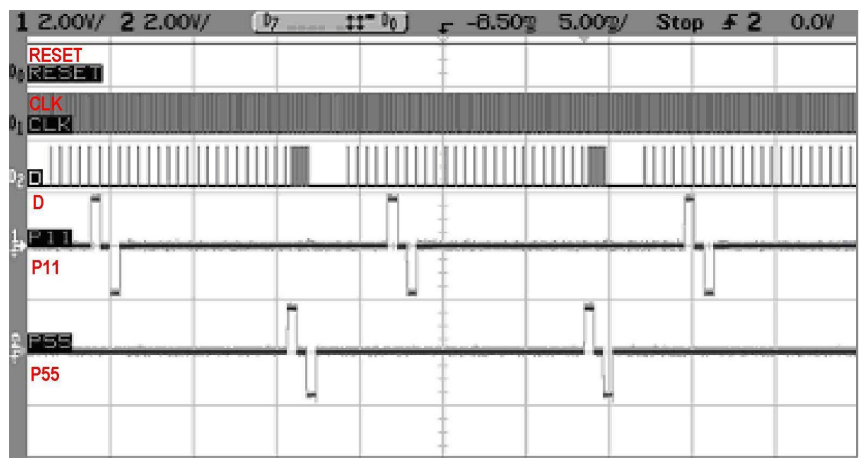

(g) P51 - P55

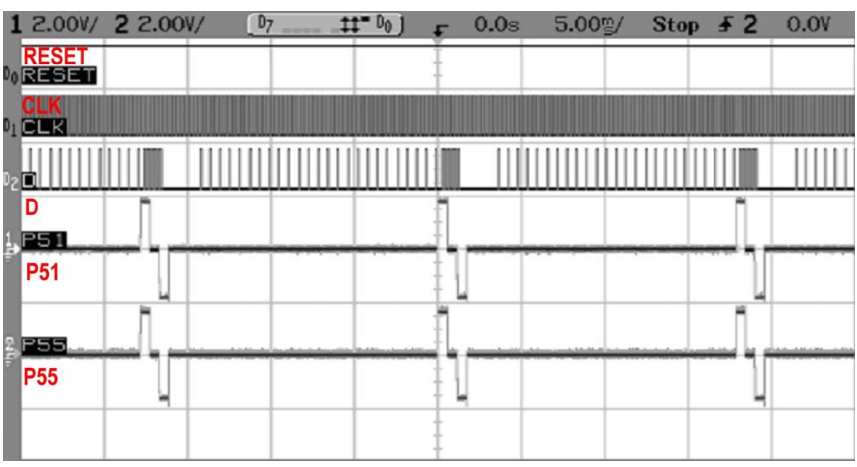

Fig. (18). Data loaded is $0 \mathrm{x} 40$ in each channel. Measured amplitude is $1.6 \mathrm{~V}$.

The specifications and performance of NIC are given in Table $\mathbf{3}$ for $13.889 \mathrm{KHz}$ clock used for testing.

\section{CONCLUSION}

A prototype $5 \times 5$ array neural implant chip is designed, fabricated, and tested. $0.5 \mu \mathrm{m}$ CMOS technology is used to fabricate it. The chip is fabricated through MOSIS. The vital part of chip i.e. neural stimulator is scaleable i.e. to increase the array size we are to add as many columns of probes as we want and stimulate them with the others by biphasic current stimulus simultaneously maintaining the persistence of vision. The parallel multiplexing technique thus makes us 
Table 3. NIC's Specifications and Performance for $13.889 \mathrm{KHz}$ Clock

\begin{tabular}{|c|c|}
\hline Parameters & Specifications/performance \\
\hline Technology & CMOS $0.5 \mathrm{~mm}$ \\
\hline Die size & $3 \mathrm{~mm} \times 3 \mathrm{~mm}$ \\
\hline Probe type & Donut probe \\
\hline Number of probes & $5 \times 5$ array ( 25 probes) \\
\hline Resolution of probes & $150 \mu \mathrm{m} \times 150 \mu \mathrm{m}$ \\
\hline Total area of probes & $750 \mu \mathrm{m} \times 750 \mu \mathrm{m}$ \\
\hline Number of current stimulator & 5 \\
\hline Current Stimulator & 8 bits \\
\hline Supply voltage & $5 \mathrm{~V}($ or $3 \mathrm{~V})$ \\
\hline Resolution of current stimulator & $2.5 \mu \mathrm{A}$ \\
\hline Current stimulator output(for input 0-BE) & $0-400 \mu A^{\dagger}($ Linear range $)$ \\
\hline Current stimulator output(for max. input FF) & $430 \mu \mathrm{A}^{\dagger}$ (max.) \\
\hline Types of waveform(software configurable) & $\begin{array}{l}\text { Monophasic (anodic) } \\
\text { Monophasic (cathodic) } \\
\text { Biphasic(with interphase delay) } \\
\text { Biphasic(without interphase delay) }\end{array}$ \\
\hline Pulse width(programmable by 6 -bit counter) & $0-2.88 \mathrm{~ms}$ \\
\hline Data rate & $13.889 \mathrm{Kbits} / \mathrm{sec}^{\ddagger}$ \\
\hline Frame rate & 55.94 frames $/ \mathrm{sec}^{\ddagger}$ \\
\hline Power consumption (no load) & $\begin{array}{l}1.59 \mathrm{~mW} \text { at } 3 \mathrm{~V} \\
13.70 \mathrm{~mW} \text { at } 5 \mathrm{~V}\end{array}$ \\
\hline Power consumption (full load) & $\begin{array}{l}2.44 \mathrm{~mW} \text { at } 3 \mathrm{~V} \\
18.65 \mathrm{~mW} \text { at } 5 \mathrm{~V}\end{array}$ \\
\hline
\end{tabular}

possible to increase the $5 \times 5$ array, but does not allow us to increase the row as that will exceed the limit of persistence of vision. It is to note here that with the addition of each column, one additional CS is required with the bigger DRR. Now, with this solution of microsystem, the limitation lies with the probes. Donut probes, which have better resolution than the conventional probes, are used in this design. These probes definitely helped us crowd more probes in a smaller area; but to increase the resolution further, we are to place the probes as close to the target cells as possible so that the required electric field penetration (here $20 \mu \mathrm{m}$ ) is reduced, which will reduce the required stimulation current (here $15.8 \mu \mathrm{A}$ ) and help us increase the probe resolution (which is $150 \mu \mathrm{m} \times 150 \mu \mathrm{m}$ for $20 \mu \mathrm{m}$ penetration) further.

Unlike others, our NS has onboard donut probes that eliminate the need of wiring them from the chip. It is also possible to design the microsystems of wireless receiver in NIC to make it completely wireless or connect NIC to the wireless receiver through only four wires (CLK, RXD, $V_{\mathrm{dd}}$, and $\mathrm{V}_{\mathrm{ss}}$,). NIC uses external clock making it suitable to tune it to any data rate. For stimulation, NIC doesn't need address as is found in most of the prostheses design. Sequential stimulation of each row by the clock is saving us from the wireless address transmission overhead. Programmable
BWC and high resolution CS has made us possible to fine tune NIC to suit the need of wide varieties of patients.

\section{REFERENCES}

[1] Liu W, Vichienchom K, Clements M, et al. A Neuro-stimulus Chip with Telemetry Unit for Retinal Prosthetic Device. IEEE Journal of Solid-State Circuits 2000; 35(10): 1487-97.

[2] Chow A, Chow V. Sub-retinal electrical stimulation of rabbit retina. Neuroscience Lett 1997; 225: 13-6.

[3] Chow AY, Pardue MT, Chow VY, et al. Implantation of Silicon Chip Microphotodiodes Arrays into the Cat Subretinal Space. IEEE Trans on Neural Systems and Rehabilitation Engineering 2001; 9(1): 86-95.

[4] Chow AY, Peachey NS. Subretinal microphotodiode array retinal prosthesis. Ophthalmic Research 1998; 30(3): 195-8.

[5] Schubert MB, Stelzle M, Graf M, et al. Subretinal implants for the recovery of vision. Proc of the IEEE Int'l Conf on Systems, Man, and Cybernetics 1999; 376-81.

[6] Zrenner E, Stett A, Weiss S, et al. Can Subretinal Microphotodiodes Successfully Replace Degenerated Photoreceptors? Vision Res 1999; 39: 2555-67.

[7] Humayun M, E. de Juan J, J. Weiland, et al. Pattern electrical stimulation of the human retina. Vision Res 1999; 39: 2569-76.

[8] Humayun MS, Freda R, Fine I, et al. Implanted intraocular retinal prosthesis in six blind subjects Proc of the ARVO annual meeting; 2005; Fort Lauderdale (Florida) 2005. p. 1140-45.

[9] Peachey NS, Chow AY. Subretinal implantation of semiconductorbased photodiodes: progress and challenges. J Rehabil Res Dev 1999; 36: 372-8.

[10] Peyman G, Chow AY, Liang C, Chow VY, Perlman JI, Peachey NS. Subretinal semiconductor microphotodiode array. Ophthalmic Surg Lasers 1998; 29: 234-41. 
[11] Jensen RJ, Ziv OR, Rizzo JF. Responses of rabbit retinal ganglion cells to electrical stimulation with an epiretinal electrode. J Neural Eng 2005; 2: S16-S21.

[12] Eckmiller RE, Baruth O, Neumann D. Learning retinal encoder RE*: results from dialog-based tuning in human with normal vision ARVO Abstracts, Invest Ophthalmol Vis Sci 2005; 5266/B469.

[13] Eckmiller R. Learning Retinal Implants with Epiretinal Contacts. Ophthalmic Res 1997; 29: 281-89.

[14] Mokwa W. Ophthalmic implants. Proceedings of the IEEE sensors; 2003. p. $980-86$.

[15] Mokwa W, Schnakenberg U. Implantable microdevices. Proceedings of the 13th European Conf on Solid-State Transducers (EUROSENSORS XIII). Den Hague, Netherlands; 1999.

[16] Meyer JU. Retina implant--a bioMEMS challenge. Sens Actuators A. 2002; 97-98: 1-9.

[17] Grumet AE. Electric stimulation parameters for an epi-retinal prosthesis [Dissertation]: Massachusetts Institute of Technology; 1999.

[18] Cogan SF. Microelectrode coatings for neural stimulation and recording. The 25th Annual International Conference of the IEEE EMBS; 2003 Sept 17-21; Cancun, Mexico; 2003. p. 3798-801.

[19] Rizzo JF. Methods and Perceptual Thresholds for Short-Term Electrical Stimulation of Human Retina with Microelectrodes Arrays. Invest Ophthalmol Vis Sci 2003; 44(12): 5355-61.
[20] Humayun MS, E. de Juan J, Dagnelie G, Greenberg R, Propst RH, Phillips H. Visual Perception Elicited by Electrical Stimulation of Retina in Blind Humans. Arch Ophthalmol 1996; 114: 40-6.

[21] Palanker DV, Vankov A, Huie P, Baccus S. Design of highresolution optoelectronic retinal prosthesis. J Neural Eng 2005; 2: S105-S20.

[22] Talukder MI. Implantable Neural Stimulation and Neural Response Reading Microsystems Design for Wireless Retinal and Auditory Prostheses [Dissertation]: Wayne State University; 2007.

[23] Grumet AE, John L. Wyatt J, Joseph F, Rizzo I. Multi-electrode stimulation and recording in the isolated retina. J Neurosci Methods 2000; 101: 31-42.

[24] Talukder MI, Siy P, Auner GW. Donut Probe Promises the Best Resolution, and the Least Potential Drop than the Conventional Probes used in Biosensors. proceedings of the 2006 IEEE Sensors Applications Symposium; 2006; Houston, Texas USA; 2006. p. 18 23.

[25] Trieu HK, Ewe L, Mokwa W, Schwarz M, Hostica BJ. Flexible Silicon Structures For A Retina Implant IEEE Transactions. 1998; 10(VI): 515-9 VI.

[26] Kelly SK. A system for efficient neural stimulation with energy recovery [Dissertation]: Massachusetts Institute of Technology; 2003.

(c) Talukder et al.; Licensee Bentham Open.

This is an open access article distributed under the terms of the Creative Commons Attribution License (http://creativecommons.org/license/by/2.5/), which permits unrestrictive use, distribution, and reproduction in any medium, provided the original work is properly cited. 